\title{
The Challenges Saudi Women Face at Work
}

\author{
Lama Hakem \\ $253 \mathrm{NE} 2^{\text {nd }}$ street, Apt 3708 \\ Miami, FL 33132 \\ Email: Lama.m.hakem@gmail.com
}

Received: February 07, 2017 Accepted: February 28, 2017 Published: March 11, 2017

doi:10.5296/ijhrs.v7i1.10697 URL: http://dx.doi.org/10.5296/ijhrs.v7i1.10697

\begin{abstract}
While women have all the rights to work and be in charge of powerful positions, in some countries women continue to struggle to be accepted as empowered and productive individuals. In Saudi Arabia, women are facing many challenges with regard to formal political and social participation including their participation in the labor sector. The purpose of this qualitative study is to investigate the obstacles and the impediments that Saudi working women face in order to succeed. This study examines the role of Saudi women in the labor sector and the job market taking into account the social barriers, the religious point of view, the government role, and cultural complexities.
\end{abstract}

Keywords: Saudi women, Work, Challenges, Qualitative method, Equal opportunities, Dispute resolution 


\section{Introduction}

Saudi women don't have enough opportunities compared to other women due to cultural norms and social traditions, they only started working in many field that were occupied by men for a long time last few years when King Abdullah Bin Abdelaziz's announcement in 2011 that Saudi women are allowed to work for shops that sells women's necessities. However, as the system tries to propel those women forward, the society pushes the women backward and does not support them.

While this step expands women's rights in Saudi Arabia, it also increases pressure on women as they may face attacks by people in the society who disagree with having women in public and social positions. Therefore, the current study is important in order to find the major challenges and barriers that Saudi women face in their social and public participation as well as to give some suggestions for overcoming these obstacles. Moreover, the purpose of this study is to investigate the effect of government's role regarding this conflict. Also, it focuses on the interpersonal strategies that result from social and cultural barriers experienced by Saudi females when they started to enter the public and the social sphere. Gabri (2012) found that worker women in Saudi Arabia face many obstacles such as social norms, gender discrimination, transportation, and low wages. The researcher added that, although Saudi women prove to the society their ability, their ambition, and their adaptation to changes in economic, social, and cultural variables, the pressures and barriers are so great that they are prevented from discussing these issues with the people in charge. The results of another study highlighted difficulties including transportation, funds, and acceptance from the society (Alhabidi, 2013).Additional obstacles that prevent women from being active in public life include 1) the historical culture which is driven by tradition and not from Islam which limits the role of women in societies; 2) the problem of illiteracy which prevents women not only from knowing their legal rights but also having the ability to control and legalize their activities in the society; and 3) the big gap between the constitution and the law which makes it impossible to apply equality in reality resulting in women's exclusion from decision-making and political participation (Daghi, 2006).

The purpose of this qualitative method study is to investigate the barriers that affect Saudi women participation in the social and public sphere including the labor sector and the role of the government that helps women to overcome these barriers.

The objectives of the study are: investigating the barriers and obstacles that Saudi women in public and social positions, might face from the Saudi societies and the Saudi culture. Also, examining the relationship between society's knowledge about the need of having women in the labor market and the attitude towards those women. In addition, exploring the implications of having Saudi women in the labor sector on the society. Moreover, identifying the strategies that may decrease the obstacles faced by women in terms of public service.

\subsection{Social and Cultural Difficulties}

Customs and traditions in the Middle East in general are different from one society to another but for Saudi Arabia in particular. According to Abu Hanieh (2008), the unique situation of 
Muslim women in such societies makes the discussion and the negotiation of those women's rights and issues difficult and under strict control. Abu Hanieh (2008) in discussing the status of women in the Jordanian society, which is one of the Middle Eastern countries, observed that the patriarchal nature of the society which is governed by a tribal social structure makes it difficult to accept the fact that women can have effective participation outside the context of family and home. In addition, society's fear of any change in women's roles is another reason because many societies still strongly adhere to the role of women as wife and mother and, therefore, find it difficult to see women outside of their homes engaging in labor market. These perceptions make women's participation very weak and minimal.

One obstacle evident in Arab societies is that the societies are not mixed where men and women can commingle in the same place. Another reason that makes women's engagement in society and labor force difficult is the strict condition that government imposes in order to give women permission to participate in public life and the public sector. Some movements in the Middle East, especially in Jordan, tried to eliminate some of these restrictions by employing and recruiting women in their facilities in order to give women the chance to represent themselves in public arenas. Muslim women now have more chances and abilities that allow them to change and renew the thoughts of Arab societies. Abu Hanieh further observed that women in Arab countries are more confident, believing that they can make major changes and have an impact on their societies because they have both the right to express themselves and have communication skills so they can easily deliver their message and reach wide segments of society.

Social structure affects the education and employment opportunities for women (Paxton et al., 2007). In addition, the societies are accustomed to seeing women as followers and not as leaders. Sadie further noted that the legal status of women as minorities is another obstacle because in many cultures women are born under their father's guardianship and after marriage this guardianship is transferred to their husbands, and in the event of the husband's death it transferred to the husband's heir (2005). Karolak (2012) pointed to some serious obstacles such as the traditional division of gender roles, reinforced patriarchy, and the separated sphere; however, these barriers will vanish over time. Sabbagh (2005) discussed that many Arab countries started to improve women's status even if the mechanisms of these improvements did not match with the patriarchal social structure; they are doing that in order to gain international recognition. Sabbagh also discussed the effect of tribalism as one of the obstacles for women's advancement in many fields (2005). In another study Kelly (2009) discussed that women in the Arab region rarely participate in politics and private sectors. To account for the absence of women in these fields she offered a couple of reasons including gender discrimination and family laws that give a husband the permission to control his wife's rights such as the right to work and travel.

\subsection{Islamic Point of View}

Islam is a religion that advocates for women's rights and considers women as equal partners with men in rights and duties. Rajkhan (2014) mentioned in a study about Saudi women that "Women's issues in Saudi society are often mistakenly connected to Islamic teachings" (p. 8). 
Kelly (2009) discussed how the conservative interpretation of Islamic law in some Islamic countries makes it hard for women to participate in the public sphere.Daghi (2006) also observed that Islamic thought had an impact on women's issues with concern for different aspects such as the mix of culture and traditions with religion, the dominant role of men, the common view in Islamic societies that women's rights come from secular society and western civilization, and the idea that some women's movements raise slogans against men and promote a world without men. The role of Wahabbi movements in Saudi Arabia and the attending ideology of eliminating women from the public sphere must be mentioned. According to Najd (2004), Wahhabi movements believe that women's rights should be suppressed from the beginning in order to avoid more demands in the future in keeping with their agenda of keeping women in the dark. Educational opportunities for female students are also restricted; for example, female students cannot enroll in engineering, agriculture, and media departments because it is believed that these fields are only fit for males. That's limit women's opportunity to compete in many fields in the labor market.

\subsection{Gender Gap and Gender Segregation}

According to Al-Rasheed (2012) Saudi Arabia ranked 129 out of 134 in the gender gap index. According to Abu Hanieh (2008), in most Arab countries men and women have separate societies. Men have to be surrounded by men, and women have to be surrounded by women. Alhabidi (2013) found that girls face more conditions that infringe upon their rights and do not protect their living standards when compared to boys. Saudi society has very restricted views toward gender and women's right; however, the new transformation in culture changed some values and beliefs in the society (Alhabidi, 2013). In addition, many dramatic events happened in the Middle East including Saudi Arabia that changed women's status so they can be in charge and occupy significant positions in these countries; however, people accept these changes differently which affects the progress of the changes. According to McGlen and Sarkees (1993), "specific gender differentiation is best explained as a social construct, or an artifact of a culture and social order that assigns women to positions of interiority, low status, and little power." (p. 11).

Ross (2008) also observed that women have limited opportunities and power because of gender segregation in the labor markets. Mtango (2004) discussed how the Saudi educational system segregates males and females in schools and universities, adding that gender segregation in Saudi Arabia limits Saudi women's access to educational facilities such as libraries which affects the women's learning experience. According to Reskin (1993), "segregation facilitates unequal treatment by subjecting groups to different reward systems" (p. 241). In addition, Reskin observed that gender segregation is not only a physical separation, it is also separates the society into two groups: one dominant and the other one subordinate (1993). In a study about Saudi Arabia Rajkhan (2014) discussed that "The notion that women are only able to work in segregated spheres where they cannot be seen by strange men is still dominant" (p. 7).

\subsection{Saudi Women between the Past and the Present}

Over the last several decades, women's status in Saudi Arabia has changed dramatically as a 
result of the on-going efforts of the Saudi kings behind the reforms. Clergy and religious establishments had a big role of these changes in the past; however, King Abdullah's decisions in favor of women show that there is a gap between clergies and the political decision-making in Saudi Arabia (Karolak, 2013).

The West's intervention in Iraq in 1991 had the ripple effect of increasing religious restrictive policies toward women and gender separation (Karolak, 2013). In 2004 the Saudi National Dialogue Forum focused on women's rights to participate in the public sphere and the importance of changing women's status in Saudi Arabia (Karolak, 2013). Most of female activists face difficulties from members of the society (including both men and women) which, therefore, limits support and does not promote change in the legislation toward women, but it does help to discuss topics that they were not be able to discuss in the past (Karolak, 2013).

King Abdullah puts reforming women's status amongst the top items of his agenda (Karolak, 2013). He believes in the importance of giving Saudi women their full rights including social and cultural rights which are often considered to be the lowest in the Middle East (Karolak, 2013). Females are included in his scholarship program which sponsors students to study abroad. In 2012, he enforced the employment of women at shops, especially shops that sell female products, which, in turn, creates new job opportunities for women. This decision came against the religious establishment's vision of Saudi society. Although the differences between King Abdullah's vision of Saudi society and the vision of clergy are very obvious, this divergence does not decrease the importance of the religious establishment's role (Karolak, 2013). According to Rajkhan, (2014), “Since 2000, women's participation rate in the Saudi labor force has nearly tripled, from 5.4 percent to 15.4 percent in 2013" (p. 20). All of the previous improvements are signs of more and significant improvements in the future.

Saudi women are still confined by the guardianship law which should be amended in the near future. According to Karolak (2013), The lack of women's participation in the public sphere due to "mixed gendered environment, the problems of transportation, shortage of day care facilities as well as the guardianship system make it difficult for women to undertake employment" (p. 14). In addition, current improvements in women's status includes giving them the opportunity to study abroad, to be in high positions, and to be able to be a part of the economic growth; all of these improvements will have the effect of changing the mentalities of Saudi youth toward women's role in the society (Karolak, 2013).

Unsurprisingly, changes related to women's status in Saudi Arabia'susually face objection from the religious establishment and clerics, and related decisions changing women's status are unlikely to be successful or achieved if not issued by the king (Al-Heis, 2011). The state wants to reform and change the women's status while the religious establishment and clerics share fear and concerns toward any reform. This contrast in view results in clashes between politicians and clerics and causes disharmony in the long-held and historical relationship in Saudi Arabia (Al-Heis, 2011). ). Al-Heis also discussed three important reasons why the Saudi government was encouraged to reform women's status. The first one was that Saudi Arabia wanted to improve its image in front of the world, especially after joining the World 
Trade Organization and signing the Convention for the Elimination of all forms of Discrimination against Women (CEDAW). The second reason was the feminist movements working to eliminate the discrimination and criticism against women and guarantee women their rights as a citizen. The third reason, which is the most significant reason, is the difficulties that Saudi women face and the efforts that the state is trying to make in order to improve this status (2011). Al-Heis (2013) concluded that "The two main obstacles impeding progress on women's rights are the ones discussed above: religious thought in the state and the state's political economy" (p. 6). He added that women have to be present and participate in institutions in an active way in order to be able to reach and enjoy their rights. In her book A Most Masculine State: Gender, Politics and Religion in Saudi Arabia, Al-Rasheed (2013) explained that as a Saudi female she sees that Saudi women were totally eliminated from the economic and political sphere; however, now with communication technology now including media women's voices can be heard in different spheres.

\section{Method}

\subsection{Participants}

Eight to fifteen participants were recruited for the study. All of them were Saudi women nationalities, speak and read in English, and have been working for more than two years in different positions. The survey included 11 open-ended interview questions, which were used to facilitate open expression of the lived experiences of the Saudi women in power, without third party involvement (Pattons, 2002). All the participants lived in the main big cities in Saudi Arabia (Jeddha, Riyadh, and Dammam), and it was really hard to find participants from small cities. That's because people who live in small cities are more conservative and have negative attitude toward women's public appearance. In addition, most of them do not allow their wives, daughters, and sisters to work in a mixed work environment. However, people who live in big cities might be more accepting of the idea of women's empowerment. The participants' ages were from 32 to 46, and all have at least a bachelor degree.

\subsection{Procedure}

This study used a qualitative design with a phenomenological approach. The phenomenological case study approach allows for collection of detailed descriptions of the perceptions and experiences of Saudi women. The open-ended questions of the researcher-designed interview instrument elicited detailed responses from the interviewees. The researcher divided the questions into categories in order to organize the findings of the study. These categories were only for the research which helped to come up with detailed findings and provided more explanation of each category. The determination of each category was based on the questions and the answers of each question. A semi-structured interview with open-ended questions was administered to examine the lived experiences of Saudis working women. A qualitative phenomenological design was the best choice for this particular study because such a design supported an open atmosphere conducive to in-depth interviews. The participants had the opportunity to interact with the interviewer and reflect on significant outcomes from their past (McDougall, 2000). A unique numeric identifier was assigned to each participant to protect confidentiality. The researcher's Institutional Review 
Board approved analysis of this data.

Moustakas' (1994) approach was used to process the data analysis for the phenomenological study from the interview instrument. According to Moustakas' (1994), the data analysis involved different steps starting with reading the transcripts of the interviews several times in order to identify the significant statements. These statements were provided in a table with short phrases about the deep meaning of each statement. This step is called horizonalization (Moustakas, 1994). The next step in Moustakas' approach is clustering the non-repetitive and non-overlapping data into themes of meaning. Then, the significant statements and themes were used to write the textual and structural descriptions (Moustakas, 1994). According to Moustakas, textual description is a full description about the participants' experience. The structural description is a description about the contextual environment in the Saudi community that influences how the participants experienced such phenomenon. The last step was the composite description which is about the essence of the phenomenon.

For each interview, units of meaning were outlined, following the recommendations of Miles and Huberman (1994) and Hoepfl (1997) that analysis should be an iterative process. At this point in the analysis, the research questions were not fully addressed; however, key words and phrases could be extracted from the transcript or interview notes (Groenewald, 2004; Hycner, 1985). This process included making notes in the margins of the compiled material, and these notes became the initial coding of the qualitative data, with the blocks of text extracted and coded from the material. This blocking condenses participant responses, but still retains the essence of the interview, while providing the ability to further organize and depict the emergent themes.

After general unites of meaning were defined, the research questions were compared to the participant responses. The units of meaning which address the central research questions were noted as relevant to the study. Units of meaning which were irrelevant were not recorded (Groenewald, 2004; Hycner, 1985). Following this strategy, the relevant units were organized and redundant themes may be eliminated, but as Hycner (1985) cautioned, the repetition of meanings may be very important to the study. Therefore, the weight participants placed on themes and the way things were said were considered as well. These impressions were noted in the after interview notes.

\section{Analysis and Result}

First of all the interviews were transcribed and printed. Second, the data were analyzed to find the repeated words and then themes were identified based on those words. The researcher read the text word by word and line by line and investigated the word repetition and frequency during the interviews. Analyzing the data helped to find the similarities and the differences in each of the responses. Third, the themes were highlighted after evaluating and analyzing the participants' responses. Finally, contrast methods were used to look closely at phrases and words such as "lately," "as a result," "because," and "finally" which helped to determine the conceptual relationships. After analyzing the content of the interviews with Saudi women, the data were categorized depending on factors that related to the participants' family life and social life. This step analyzed the data of each individual in more detail. 
The key points from each participant were labeled regrouped again into higher commonality in order to come up with the major categories for all the interviews. The researcher came up with seven major categories that stated in the following table.

(Insert table 1 about here)

\subsection{King Abdullah's role}

The researcher found that Most of the responses from the interviews discussed the positive role of King Abdulla toward improving women's status. The participants discussed how King Abdulla gave women the permission not only to work but also to compete in the market and work in positions that used to be held by men only. Also, they supported the point that King Abdullah helped Saudi women to be who they are today. The participant mentioned the dramatic increase in the rate of female employment. This increase came along with the new regulations in labor market which allow women to work in positions they have never been in during Saudi Arabia history. Some participants noted that the opportunity for Saudi women now is unprecedented.

It was clear that the majority of the participants praised King Abdullah's role in developing and improving women's status in Saudi Arabia. The support from King Abdulla allows Saudi women to have opportunities to participate in the public sphere and be part of the economic and political enhancements. Consequently, his era has made a change in the history of Saudi Arabia with regard to all of the changes in the regulations that supported women in public. As the participants explained, King Abdulla's role has a positive effect for a large percentage of women who are now able to work in different fields including the political field. Furthermore, seeing a Saudi woman for the first time as a deputy minister and educator of women's affairs in King Abdulla's era provides proof of his unlimited support to women politically and publicly. Participants found that without the support from King Abdulla and the government, they would not be able to be in these positions today.

\subsection{Social role}

The participants provided detailed responses during the interviews about social role including the social barriers and the social reform movements. One of the main social barriers was the traditions and the cultures that still govern most of the Saudi's lifestyle in many different aspects. The participants reported that they were negatively affected by the social barriers (traditions). Also, some of the participants mentioned that living in a patriarchal society makes their mission harder. In addition, they highlighted that gender segregation is one of the obstacles in Saudi which does not allow women to enter and gain access to certain locations. The participants mentioned that the society believes that segregation is very important to protect the women; however, this segregation, especially in work environments, limits Saudi women's access to the labor market. Furthermore, segregation places so many restrictions on Saudi women's mobility. Moreover, it affects the freedom of communication between males and females. Also, gender segregation in the work place has a negative impact on increasing females' work experience.

Many of the participants discussed another important barrier which is the male guardian. 
Saudi women need male guardians to get travel permission, to renew passports, and to get most of the official government paper work done which is limiting their personal improvements in many fields. Also, the participants did not see that men are facing the same barriers; in other words, social barriers do not exist in the men's world. Moreover, men always have the acceptance from the society.

Participants were to some degree scared of being in such positions and to face all of the cultural and the traditional barriers as a result of a conservative society which has a phobia toward any changes in the society. However, the participants' fears were transformed to a challenge once they started to feel that this is their mission to prove themselves. Although women tried to stay strong and positive to reach success, the social rejections had a negative impact on their progress. The stereotypes about women being less productive affect their self-esteem and their self-confidence. However, as is the case with most of the stereotypes, the truth is far different from the reality. Saudi women prove that they are heroes and survivors; despite all of the social barriers, they still work hard and set realistic expectations based on the context in which they operate. Although social barriers are exaggerated in the Saudi society, it also occurs in other societies. Nevertheless, the society started to change; people who did not accept women working in public as stores managers, as cashiers, and as candidates in the Shura Council, as well as people who were resistant to being under women's supervision or working with them as peers, will change over time and look up to them and believe in them. It is a matter of time, no more, no less. Every society resists social movements at the beginning; however, with time the society will get used to the changes.

\subsection{Personal experience}

Most of the participants' experiences were similar since they live in the same society. Most of the participants reported that men resist working under women's supervision. Also, some of the male employees left their jobs and do not accept any jobs where they will be supervised by a female. Another important point was mentioned by the participants when they discussed that women have to work three to four times harder than men to get recognized for the same work a male performs.

\subsection{Personal strength}

It is very important to mention that when the participants discussed their personal strength and motivations, it was very clear that they gained most of that strength during their experiences to overcome barriers. The participants reported their concerns about failing and their ability to face the conservative traditions in the Saudi society. The participants presented different strategies that helped them to overcome barriers and cope with the challenges. The most commonly reported strategies included the following: be educated, have the desire to change the view toward women don't listen to criticism, and be competitive. All the participants believe that Saudi women are successful, and they have the strength to overcome barriers and prove their capability to compete with males.

\subsection{The government role}

Most of the participants discussed the government's role from different perspectives 
including the regulations, the legislations, and the law. The participants indicated that the unclear systems and regulations are one of biggest issues that negatively affect their work flow. Since women are not allowed to enter many government departments without a male guardian, some of the participants suggested that there should be a female section in every government sector that has a qualified female employee. In addition, they mentioned that most of the female government sections, if any, are only for submitting documents, taking photos, or fingerprinting and the real work has to get done in the male sections. So, the participates suggested that the female sections should have a full authority to finish the work and make decisions regarding any case without going back to the male department.

The official government is playing a big role in order to improve women's status in Saudi Arabia by reforming the current regulations and trying to give both males and females equal access to the labor market.

\subsection{More barriers}

Some women, especially those who work as cashiers and in stores, are facing more barriers than women who work in higher positions such as political positions. Stores employees interact more with customers face to face which is more challenging. They face people who come from different backgrounds, different levels of education, and different mentalities. In addition, the social culture still does not accept seeing women working in such positions. Women who started to work in these positions - with minimal experience for most of them-face verbal insults from some customers. Some people who insult them verbally regarding their positions and how do they work in these places because these positions are only for men. Also, some customers might insult the employees' family as well, because the families allow their women to work in public and interact with men. On the other hand, women in higher positions such as political positions and mangers interact less with people. However, they still face rejection including insults from other people. Although the insulting is not face to face compared to women who work in stores, it is still effects them negatively.

Saudi females were surprised to find that the social rejection of having women in the public sphere was not only discouraged by males only; some females also do not support the idea of empowering women and allowing them work especially in mixed work environments. Although the Saudi females were initially worried about how they would be received by the society generally, as well as by their families specifically, the data revealed that they had reasons to worry because having Saudi females work in public positions just started few years ago which is considered new phenomenon. In addition, although the females succeeded with their work, they still had to overcome various stressors such as coping with difficulties from being in a new experience as well as social-related stressors, for example, related to being surrounded by and dealing with males in the work place. Consequently, Saudi females utilized personal strength strategies and employed motivations to help them succeed.

The data proved that the number of female employees increased and the unemployment rate of females decreased. In this sense, the barriers did not prevent females from working in public and being publicly recognized. Rather than being socially isolated and economically ineffective, there was a desire to be financially independent and socially interactive. While 
Saudi females did not engage in any act that would be an affront to their religion, families, and country, people will realize one day that women's public participation will have a better impact in the Saudi society specifically, and the whole country generally.

\subsection{Sociological interpretations}

First, it is really important to consider the background history and the structure of Saudi society. The Saudi community has a tribal conservative nature in which women are not allowed to interact with unrelated men. Also, the community has a fear of the idea of modernization and Westernization that might change their community structures. Second, most of people in the society see things through religious eyes. Many Islamic scholars in Saudi Arabia issued religious rulings that prohibited Saudi females from working in mixed environments. They consider women working in public as anti-Islamic and that it should not be acceptable in any Islamic society. Also, they suggested that women should look for jobs only where they do not have to interact with men. The reason of this rejection from the Islamic scholars is that they do not want to open the door for any kind of sexual attractions and sexual temptations among men and women in the community. The angry attitude from the Islamic scholars in Saudi Arabia regarding females working in public positions had a negative impact on the level of acceptance for the idea among the community. Interestingly, the contradiction between the official government ruling and the Islamic scholars' ruling put the community in a puzzled situation where they did not really know who is right and who is wrong. Also, it makes it hard for people to accept the new ruling and cope with the social changes. Although they want to have jobs and participate in the socioeconomic improvements of the community, they are scared of committing sins as a result of working in mixed environments. This might cause incredible psychological struggle among Saudi females. Also, this creates negative feelings by being stuck between personal goals from one side and religion and beliefs from the other side. In fact, the rejection of having women work in public positions does not come from Islam; it comes from the patriarchal community that wants to keep women in their places. Per the data, it could be understood that these barriers are temperedly due to the sudden changes in the community norms and will not be permanent.

\section{Limitations}

One of the limitations which must be considered when the researcher uses an interview method to collect the data is the level of the cooperation from the participants. While interview is one of the common qualitative research instruments, some participants could give exaggerated information about the issue. The result of the study cannot be generalized due to the small sample size. However, the aim of this research was not to collect data in order to generalize it; it was collected in order to provide a better understanding about the experience of Saudi females who are facing social barriers regarding their political and public participation. The lack of diversity regarding demographic locations of the participants had a significant impact on the findings. All of the participants live in three main cities in Saudi Arabia (Jeddah, Riyadh, and Dammam). The participants represented a narrow range of ages. Also, all of the participants have at least a bachelor degree which means they attended colleges. As a result, none of the participants had lower level of education than a bachelor 
degree which means there was no diversity in the level of education. The lack of knowledge among the society about the importance of such a study causes a lack of interest in participation in the study. In addition, there was a lack of finding enough literature related to women in Saudi Arabia.

\section{Conclusion}

In any conservative society such as the Saudi one, people have limited view of women and gender roles apparently do not allow women to enjoy their rights. It was expected that Saudi women would face these barriers. Saudi women should break away from the gender traditions that are imposed by the community under the name of religion. They already started to be part of the public participants when King Abdulla opened the door for them and allowed them to have this right.

This topic is significant since it discusses a social phenomenon in the Saudi community. Also, such a topic breaks the silence toward significant issues that many Saudi women face and shows the reality from Saudi women's perspective. Women who were involved in the study were admirable in their determination to accept the social challenges to become part of the social improvements and add to themselves and their community. These women are having a very interesting experience because they are running against the social and cultural norms which limit women's activities and do not allow women to interact face to face with males. They are in positions that were not previously preceded by females in the whole history of Saudi Arabia; so this time is a perfect time to examine the challenges that women face. In another words, all the participants were in positions considered to be males' domain.

Although the topic was sensitive in its nature, the participants talked about their issues and their experiences of becoming the first generation of Saudi women in public sphere. This topic will help to recognize the social and cultural barriers that most Saudi women face which, as a result, help in finding better solutions for future improvements. Improving the awareness in the society about the importance of women's role in public positions is one of the goals that must be focused on in order to have a new generation of women with less barriers and a new generation of open-minded men. Also, it helps to focus on improving some of the official government departments in order to serve Saudi women in a better way. The movement to reform women's status in Saudi Arabia has been started, and it will be continued until the Saudi society treats both males and females the same way in all aspects including education and job opportunities. The current situation of women's status proves that there are more improvements in the near future. It must be understand that while allowing women to work in public sphere will improve Saudi Arabia politically and economically, it also gives women their human rights and the equality that Islam gave to them more than 1,400 years ago. 


\section{References}

Abu Hanieh, H. (2008). Women and politics: From the perspective of Islamic movements in Jordan (M. Abu Rayyan, Trans. \& Ed.). Amman, Jordan: Friedrich-Ebert-Stiftung. Retrieved from http://library.fes.de/pdf-files/bueros/amman/05997.pdf

$\begin{array}{lllll}\text { Al-Gabri, } & \text { A. } & \text { (2012, } & \text { July } & \text { Almara'a }\end{array}$ Al-SaudiaAlamelabaynSendanAlbatalawaMatrkatSo'batAlamal [Saudi women working: Between the anvil of unemployment and the hammer of the difficulty of working]. Middle East Newspaper. Available from http://maktoob.news.yahoo.com

Alhabidi, M. (2013).Saudi women entrepreneur over coming barriers in ALKhober.(Master's thesis).Available from ProQuest Dissertations and Theses database. (UMI No. 1426640506)

Al-Heis, A. (2011). Women participation in Saudi Arabia's political arena. Report from Al Jazeera Center for Studies. Available from http://studies.aljazeera.net/en/reports/2011/11/20111127125217581492.htm

Al-Rasheed, M. (2012, February/March).The meaning of rights for women.The World Today. Retrieved from http://www.chathamhouse.org/sites/default/files/public/The\%20World\%20Today/2012/februa ry/0212alrasheed.pdf

Daghi, A. (2006). Almara'awaalmosharkaalsiyasia w aldemocratia [Women's politicalparticipation and democracy, Study in Jurisprudence and Islamic political thought]. Retrieved from http://www.e-cfr.org/ar/bo/22.doc

Groenewald, T. (2004). A phenomenological research design illustrated. International Journal of Qualitative Methods, 3(1), 1-26. Retrieved from https://www.ualberta.ca/ iiqm/backissues/3_1/pdf/groenewald.pdf

Hoepfl, M. C. (1997). Choosing qualitative research: A primer for technology education researchers.Journal of Technology Education, 9(1), 47-63.

Hycner, R.H. (1985). Some guidelines for the phenomenological analysis of interview data.Human Studies, 8(3),279-303.doi:10.1007/BF00142995

Karolak, M. (2012). Bahraini women in the 21st century: Disputed legacy of the unfinished revolution. Journal of International Women's Studies, 13(5), 5-16.

Kelly, D., \& Gibbons, M. (2008). Marketing methods ethnography: The good, the bad and the ugly. Journal of Medical Marketing, 8(4), 279-285. doi:10.1057/jmm.2008.18

Kelly, S. (2009). Recent gains and new opportunities for women's rights in the Gulf Arab states.In S. Kelly \& J. Breslin (Eds.), Women's rights in the Middle East and North Africa (Gulf ed., pp. 1-8).New York: Freedom House. Available from http://www.freedomhouse.org/ McGlen, N. E., \&Sarkees, M. R. (1993).Women in foreign policy: The insiders. New York: Routledge. 


\section{Macrothink}

International Journal of Human Resource Studies

ISSN 2162-3058 2017, Vol. 7, No. 1

McDougall, P. (2000). In-depth interviewing: The key issues of reliability and validity.Community Practitioner, 73(8), 722-724.

Miles, M. \&Huberman, A. (1994).An expanded source book: Qualitative data analysis. New York: Sage.

Mtango, S. (2004).A state of oppression?Women's rights in Saudi Arbaia. Asia-Pacific Journal on Human Rights and the Law, 5(1), 49-67.

Moustakas, C. (1994). Phenomenological research methods. London: Sage.

Najd, S. (2004, January 1).Almara'a al-Sauida Fi EtarAlharkaAlwahabbia [Saudi women in the context of the Wahhabi movement]. Retrieved from http://www.c-we.org/ar/show.art.asp?aid=13633

Pattons, M. Q. (2002). Qualitative research and evaluation methods (3rd ed.). Thousand Oaks, CA: Sage.

Paxton, P., Kunovich, S., \& Hughes, M. M. (2007).Gender in politics.Annual Review of Sociology, 33, 263-270, C-1b, 271-284. doi:10.2307/29737763

Rajkhan, S. F. (2014). Women in Saudi Arabia: Status, rights, and limitations (Master's thesis, University of Washington Bothell). Retrieved fromhttps://dlib.lib.washington.edu/researchworks/bitstream/handle/1773/25576/Rajkhan\%2 0-\%20Capstone.pdf?sequence $=1 \&$ isAllowed $=\mathrm{y}$

Reskin, B. (1993). Sex segregation in the workplace. Annual Review of Sociology, 19(1), 241-270.doi:10.1146/annurev.so.19.080193.001325

Ross, M. L. (2008). Oil, Islam, and women.The American Political Science Review, 102(1), 107-123. Retrieved from http://www.jstore.org/stable/27644501

Sabbagh, A. (2005). The Arab states: Enhancing women's political participation. In J. Ballington\& A. Karam (Eds.), Women in parliament: Beyond Numbers (Rev. ed., pp. 52-71). Stockholm: International IDEA.

Sadie, Y. (2005). Women in political decision-making in the SADC region.Women and Leadership, 19(65), 17-31. doi:10.1080/10130950.2005.9674616 


\section{Macrothink}

Table 1:

Categories and Sub-categories

Major Categories

king Abdullah's role

Social role

Personal experience

Personal strengths

The government role

The organization role (work place)
Sub-categories

Ideas about his "unlimited support to women," and "change regulations"

Perceptions about social "acceptance," "barriers," "traditions," and "culture"

Highlight "Saudi women experience" and "family role"

Ideas regarding "success," "empowerment," "motivations" and "advices"

Perceptions about "laws" and "the regulations"

Perceptions around the work place "support," and " rules" that protect women in work places

\section{Copyright Disclaimer}

Copyright for this article is retained by the author(s), with first publication rights granted to the journal.

This is an open-access article distributed under the terms and conditions of the Creative Commons Attribution license (http://creativecommons.org/licenses/by/3.0/). 